\title{
KH. M. Mahsun Adnan dan Kontribusinya Bagi Perkembangan MI Al- Adnani Kayangan Diwek Jombang
}

\section{KH. M. Mahsun Adnan and His Contribution for MI Al-Adnani Kayangan Diwek Jombang Development}

\author{
Mukani $^{1}$ \\ ${ }^{1}$ STAI Darussalam Krempyang Nganjuk \\ 1 mukani42@gmail.com
}

\begin{abstract}
The madrasa role has long been recognized by community. Based on Law Number 20 of 2003 concerning National Education System, madrasa is a national education sub-system. This article is descriptive-analytic with a qualitative approach. The data was collected through interviews, documentation and observation. The data then analyzed by non-statistics, such as data reduction, data presentation and conclusion drawing. The study describes a brief biography of KH. M. Mahsun Adnan, he was born in Nglaban, he studied at Tebuireng, after that he studied at PGA. After graduating, he then continued his study at Undar and then dedicated himself to da'wah and education until his death. The second focus is the struggle of KH. M. Mahsun Adnan toward Al-Adnani Islamic Elementary School Jombang, starting from being a pioneer, becoming the head of a madrasa, teaching in it and fighting to make the madrasa run up. So far, Al-Adnani Islamic Elementary School Jombang shows its existence continuesly in bringing forword the community arround through education.
\end{abstract}

Keyword: Contribution, Mahsun Adnan, Figure.

\begin{abstract}
Abstrak
Peran madrasah telah lama diakui oleh masyarakat. Madrasah berdasarkan UU Nomor 20 Tahun 2003 tentang Sisdiknas adalah sebagai sub sistem pendidikan nasional. Artikel ini berjenis deskriptif-analitik dengan pendekatan kualitatif. Pengumpulan data melalui wawancara, dokumentasi dan observasi. Analisis data menggunakan non-statistik, yaitu reduksi data, penyajian data dan pengambilan kesimpulan. Pembahasan tulisan ini mendeskripsikan biografi singkat KH. M. Mahsun Adnan, mulai lahir di Dusun Nglaban, menimba ilmu ke Tebuireng, PGA dan kuliah di Undar lalu mengabdikan diri bagi dakwah dan dunia pendidikan hingga wafatnya. Fokus kedua adalah perjuangan KH. M. Mahsun Adnan kepada MI Al-Adnani Kayangan, mulai dari menjadi merintis, menjadi kepala madrasah, mengajar di dalamnya hingga berjuang agar madrasah tersebut tetap berkiprah. Hingga sekarang, MI Al-Adnani Kayangan tetap menunjukkan eksistensi dalam memajukan warga masyarakat sekitar melalui dunia pendidikan
\end{abstract}

Kata Kunci: Kontribusi, Mahsun Adnan, Tokoh 


\section{Pendahuluan}

Islam memandang bahwa pendidikan sangat penting bagi manusia, agar manusia menjadi dapat menjadi hamba Allah yang tunduk dan patuh memenuhi perintah Allah. Pendidikan pada awal sejarah peradaban Islam dilakukan di masjid, yang kemudian agar tidak mengganggu ketenteraman dalam beribadah di masjid, maka dibuatlah tempat khusus yang dikenal dengan nama madrasah. Sejak saat itu terjadilah proses transformasi institusi penyelenggara pendidikan dari masjid ke madrasah.

Madrasah sampai sekarang telah menjadi salah satu model pendidikan di seluruh negara Islam maupun negara yang di dalamnya terdapat sejumlah besar komunitas masyarakat Islam, tidak terkecuali negara Indonesia. Pesantren, madrasah dan sekolah Islam mempunyai reputasi tersendiri sebagai lembaga yang bercirikan agama Islam. Sebagai lembaga pendidikan pesantren madrasah dan sekolah Islam umumnya menyelenggarakan pendidikan, bahkan karena memiliki ciri khusus yang

1Haderani. "Pesantren, Madrasah dan Sekolah Dalam Perspektif Pemikiran Pendidikan Islam," Jurnal Tarbiyah Darussalam, Vol. 4 No. 6 (2020), 13-24.

146 membedakannya dengan penyelenggaraan pendidikan lain. ${ }^{1}$

Peran madrasah telah lama diakui oleh masyarakat, misalnya tentang peradaban. Madrasah mempunyai reputasi tersendiri sebagai lembaga yang bercirikan agama Islam, yaitu sebagai lembaga pendidikan dan sebagai lembaga sosial kemasyarakatan. Sebagai lembaga pendidikan karena madrasah umumnya menyelenggarakan pendidikan, bahkan karena memiliki ciri khusus yang membedakannya dengan penyelenggaraan pendidikan lain. Sebagai lembaga sosial kemasyarakatan dibuktikan dengan diharapkannya kehadiran madrasah dalam masyarakat. Kehadiran di sini dimaksudkan dalam rangka changing and developing masyarakat. ${ }^{2}$

Madrasah berdasarkan UU Nomor 20 Tahun 2003 tentang Sisdiknas adalah sebagai sub sistem pendidikan nasional. Meskipun madrasah berada di bawah Kementerian Agama RI, namun karena merupakan sub sistem pendidikan nasional dan sekaligus merupakan bagian integral dalam sistem pendidikan nasional, maka madrasah sebenarnya masuk dalam bidang pendidikan dengan

${ }^{2}$ Sri Haningsih, "Peran Strategis Pesantren, Madrasah dan Sekolah Islam di Indonesia," ElTarbawi, Vol. 1 No. 1 (2008), 27-39. 
manajemen pemerintahan daerah, baik pemerintah propinsi maupun kabupaten/kota. Karena posisinya tersebut, pemerintah daerah seharusnya memberikan perlakuan yang sama, tanpa ada dikotomi pemberdayaan baik dalam memberikan fasilitas, sarana prasarana, pendanaan maupun perkembangan ketenagaan, tanpa ada dikotomi negeri dan swasta. ${ }^{3}$

Dalam konteks Indonesia, istilah madrasah ini telah menyatu dengan istilah sekolah formal atau perguruan di bawah binaan Kementerian Agama. Madrasah telah marak di Indonesia sebagai lembaga pendidikan sejak awal abad XX. Perkembangan madrasah pada masa awal kemerdekaan sangat terkait dengan peran Kementerian Agama yang mulai resmi berdiri sejak 3 Januari 1946. Dalam kaitan dengan perkembangan madrasah di Indonesia, Kementerian Agama menjadi andalan yang secara politis dapat mengangkat posisi madrasah sehingga memperoleh perhatian yang serius di kalangan pemimpin yang mengambil kebijakan. ${ }^{4}$

Kata madrasah dalam bahasa Arab adalah bentuk kata keterangan tempat (zharaf makan) dari kata darasa. Secara

${ }^{3}$ Hasri, "Madrasah Sebagai Lembaga Pendidikan Islam," Al-Khwarizmi, Vol. 2, No. 1 (Maret 2014), 69-84. harfiah, madrasah diartikan sebagai tempat belajar para pelajar atau tempat untuk memberikan pelajaran. Kata madrasah jika diterjemahkan dalam bahasa Indonesia berarti sekolah, kendati pada mulanya sekolah itu sendiri bukan berasal dari bahasa Indonesia melainkan dari bahasa asing, yaitu school atau scola.

Madrasah dapat dikatakan sebagai lembaga pendidikan yang sangat menonjol dalam sejarah Islam. Madrasah merupakan kelanjutan dari pendidikan masjid dan pendidikan di lembaga khan, yaitu masjid yang dilengkapi dengan asrama. Penggunaan nama madrasah untuk lembaga pendidikan Islam pada awal-awal Islam mempunyai pengertian yang berbeda dengan pengertian madrasah pada masa sekarang. Pengertian madrasah pada masa klasik Islam disebut sebagai pendidikan akademi (college). Pemberian nama lembaga pendidikan Islam untuk berbagai jenjang dengan nama madrasah ini dapat dipahami mengingat pemberian nama lebih cenderung pada fungsi esensialnya sebagai lembaga pendidikan Islam, yaitu untuk mengembangkan ilmu pengetahuan Islam dan

"Manpan Drajat, "Sejarah Madrasah di Indonesia," al-Afkar: Journal for Islamic Studies, Vol. 1 No. 1 (Januari 2018), 196-206. 
Oleh: Mukani

sekaligus menyebarluaskan paham keagamaan. ${ }^{5}$ Berdasarkan Keputusan Lokakarya Intensifikasi Pengembangan Pondok Pesantren disitu menjelaskan definisi Pondok Pesantren yaitu lembaga pendidikan Islam yang minimal terdiri dari 3 unsur, yaitu kiai/syekh/ustadz yang mendidik serta mengajar, santri dengan asramanya, dan masjid. Seorang kyai dengan para ustadz/ustadzah merupakan hirarki kekuasaan satu-satunya yang secara eksplisit diakaui dalam lingkungan pesantren sedangkan dalam lingkungan masyarakat peran kyai juga termasuk sangat sentral sebab keberadaan seoarang kyai mampu menunjang atau meningkatkan keberagamaan masyarakat sekitar.

Kehadiran seorang tokoh (kiai) saat mendirikan sebuah madrasah juga menjadi sentral. Hal ini bisa dijumpai di semua jenjang madrasah, mulai ibtidaiyah atau dasar (MI), tsanawiyah atau menengah (MTs) dan aliyah atau atas (MA). Tidak terkecuali dengan yang dijumpai di MI Al-Adnani Kayangan Diwek Jombang.6 Artikel ini akan

${ }^{5}$ Hilmi Mizani, "Pendidikan Madrasah: Kebijakan dan Sistem Madrasah di Indonesia," Jurnal Tarbiyah Islamiyah, Vol. 3 No. 2 (2013).

${ }^{6}$ Lailatul Qomariyah, "Pemanfaatan Aplikasi Kahoot Pada Evaluasi Jombang," Prosiding Seminar Nasional Sainsteknopak 2020, Universitas Hasyim Asy'ari Tebuireng Jombang, 54-60. memfokuskan kajian kepada dua hal. Pertama adalah biografi singkat $\mathrm{KH}$. Muhammad Mahsun Adnan, akrab disapa Kiai Mahsun. Kedua adalah sejarah pendirian dan profil MI Al-Adnani Kayangan Diwek Jombang.

\section{Metode}

Jenis penelitian ini adalah deskriptif-analitik. ${ }^{7}$ Deskriptif merupakan penelitian non-hipotesis, sehingga dalam langkah penelitiannya tidak perlu menggunakan hipotesis ataupun datadata statistik. ${ }^{8}$ Penelitian ini menggunakan pendekatan kualitatif (naturalistic).$^{9}$

Penelitian ini dilaksanakan mulai bulan Januari 2021 sampai dengan Juli 2021. Sumber data ${ }^{10}$ penelitian ini, jika dilihat dari tingkat validitas sumbernya, menggunakan sumber data primer dan sumber data sekunder. Dalam penelitian ini, sumber data primer yang diperoleh oleh peneliti adalah hasil wawancara dengan ketua yayasan, kepala madrasah, guru, pihak keluarga dan rekan dari Kiai Mahsun. Sedangkan sumber data sekunder yang diperoleh peneliti adalah

${ }^{7}$ Moh. Nazir, Metode Penelitian (Jakarta: Balai Aksara, 2015), 64.

8Suharsimi Arikunto, Prosedur Penelitian (Jakarta: Rineka Cipta, 2010), 21.

${ }^{9}$ S. Nasution, Metode Penelitian Naturalistik Kualitatif (Bandung: Tarsito, 2012), 2.

${ }^{10}$ Noeng Muhajir, Metodologi Penelitian Kualitatif (Yogyakarta: Reke Sarasean, 2014), 38.

el Bidayah: Journal of Islamic Elementary Education Volume 3, Nomor 2, September 2021 
data yang diperoleh langsung dari pihak-pihak yang berkaitan berupa profil madrasah dan berbagai literatur yang relevan dengan pembahasan. ${ }^{11}$

Pengumpulan data dalam penelitian ini dilakukan dengan menggunakan teknik wawancara, dokumentasi dan observasi. Wawancara digunakan untuk menggali informasi dari ketua yayasan, kepala madrasah, guru, pihak keluarga dan rekan dari Kiai Mahsun. Dokumentasi yang digunakan dalam penelitian ini adalah profil madrasah, dokumentasi EMIS, artikel jurnal, referensi terkait dan lain sebagainya. Sedangkan observasi atau pengamatan, pada penelitian ini dilakukan terhadap objek kajian, yaitu MI Al-Adnani Kayangan. ${ }^{12}$

Penelitian ini menggunakan tahap analisis data berupa non-statistik, yaitu reduksi data (reduction), penyajian data (display) dan pengambilan kesimpulan (conclusion). ${ }^{13}$ Uji keabsahan data dalam penelitian ini dilakukan dengan cara, perpanjangan pengamatan, meningkatkan ketekunan dan triangulasi, baik triangulasi sumber, triangulasi teknik pengumpulan data maupun triangulasi waktu.

\section{Temuan dan Pembahasan Temuan penelitian}

\section{Biografi Singkat KH. Mahsun}

\section{Adnan}

Kiai Mahsun lahir di Dusun Nglaban Kecamatan Diwek Jombang pada tanggal 3 Maret 1942. Beliau wafat pada hari Rabu Pahing tanggal 17 Asyura 1430 Hijriyah, bertepatan dengan tanggal 14 Januari 2009 M. ${ }^{14}$

Ayah Kiai Mahsun bernama KH. Adnan, aslinya dari Nglaban yang menikah dengan Mbah Naimah yang asli Kayangan. Pernikahan ini dikaruniai 10 anak. Lima anak meninggal dunia saat masih kecil. Sedangkan yang lima masih hidup. Kelimanya adalah Kiai Mahsun, Kiai Mahali Jombang (almarhum), Ibu Ainun yang tinggal di Desa Kalangan Peterongan, Ibu Malikah tinggal di Jakarta dan Ibu Umaiyah Malang (almarhumah).

Pendidikan dasar Kiai Mahsun dimulai dari menimba ilmu di Pondok Tebuireng lalu ke Pendidikan Guru Agama (PGA). Pendidikan tinggi

${ }^{13}$ Lexy J. Moleong, Metolodologi Penelitian Kualitatif, 178.

${ }^{14}$ Muhammad Aminuddin, ketua Yayasan AlAdnani, wawancara, 27 Februari 2021. 
diperoleh dari kampus Univesitas Darul Ulum (Undar) Jombang.

Selama menimba ilmu, guru Kiai Mahsun yang paling berpengaruh adalah KH. Adlan Ali dari Pondok Walisongo Cukir dan Gus Tohari dari Dusun Brasut Desa Gondek Mojowarno. Pengaruh ini tidak hanya ketika menimba ilmu saja. Namun juga model perjuangan dalam berdakwah mengembangkan agama Islam di Kayangan. Terutama dalam menghadapi masyarakat yang beraneka macam.

Dalam membina rumah tangga, Kiai Mahsun menikah dengan Ibu Nyai Siti Ismihah. Perempuan ini aslinya dari Dusun Klepek Desa Sukoiber Kecamatan Gudo. Saat menikah, usia Kiai Mahsun sudah menginjak 42 tahun. Dari pernikahan ini, Kiai Mahsun dikaruniai lima orang anak.

Kelima anak Kiai Mahsun yaitu Muhammad Aminuddin, Lailatul Qomariyah, Lailatus Syarifah yang menikah dengan Pak Yunus, Lailatun Nikmah yang sekarang tinggal di Surabaya dan Lailatul Badriyah. Menurut Dr. Akhmad Sauqi Ahya, dirinya adalah menantu kedua dari Kiai Mahsun, tepatnya setelah menikah dengan Lailatul
Qomariyah, yang sekarang menjadi dosen di Universitas Hasyim Asy'ari Tebuireng. "Adik paling ragil ini belum menikah dan sekarang tinggal di rumah induk bersama istri Kiai Mahsun," ujar dosen STKIP PGRI Jombang ini. ${ }^{15}$

Pada periode awal membina rumah tangga, Kiai Mahsun pernah mengontrak sebuah rumah di Desa Cukir. Tepatnya di sebelah selatan bekas stasiun Cukir. Sedangkan bekas stasiun itu sendiri juga dikontrak Kiai Mahsun untuk membuka usaha jasa penjahitan baju. Lalu keluarga Kiai Mahsun pindah tempat tinggal ke rumah Kayangan. Sedangkan bekas stasiun Cukir disewa apotek dan sekarang dijadikan warung es degan.

Hal ini dibenarkan Abdur Rokhim, salah satu karyawan penjahit dari Kiai Mahsun yang masih hidup. Dirinya bercerita bahwa ikut kerja menjadi tukang jahit pakaian ke Kiai Mahsun di Cukir sejak masih sekolah di SMK 10 Nopember Jombang. Jadi paginya dia belajar bekerja ke Kiai Mahsun, sorenya baru sekolah ke Jombang. "Itu saya lakukan sejak tahun 1990 sampai 2005," kenangnya.

${ }^{15}$ Akhmad Sauqi Ahya, menantu Kiai Mahsun, wawancara, 9 Februari 2021. 
Dirinya mengaku bekerja ke Kiai Mahsun karena teman akrab ayah kandungnya. Saat ayahnya dan Kiai Mahsun sama-sama bersekolah dasar. "Tidak hanya itu, beliau berdua bisa dibilang konco turu langgar, karena keduanya sama-sama sering tidur di mushola," imbuhnya. "Cuma Kiai Mahsun lanjut kuliah, lalu jadi guru, sedangkan ayah saya tidak lanjut kuliah dan akhirnya kerja di PG Tjoekir," bebernya.

Dulu lokasi rumah yang dikontrak Kiai Mahsun ya di bekas stasiun Cukir barat jalan raya itu. Status kepemilikannya adalah lahan sewa ke PJKA (sekarang PT KAI). Harga sewa terakhir pada tahun 2005 diakuinya sebesar Rp 47.000, per tahun. ${ }^{16}$

Setelah menimba ilmu dari kampus Undar Jombang, Kiai Mahsun kemudian mengabdikan diri dengan menjadi guru. Statusnya saat itu adalah pegawai negeri sipil (PNS) dari Departemen Agama Republik Indonesia. Kiai Mahsun ditugaskan mengajar di MI Al-Adnani Kayangan hingga pensiun. Setelah pensiun, Kiai Mahsun masih aktif mengajar di MI Al-Adnan hingga wafatnya.
Kiai Mahsun meninggal dunia tahun di awal tahun 2009 setelah lima hari dirawat di RSUD Jombang karena penyakit diabetes basah yang dideritanya. Saat meninggal dunia, usianya sudah di atas 68 tahun, karena menikahnya termasuk agak telat, menjelang usia 40 tahun. Ketika mau berangkat ke RSUD, Kiai Mahsun berwudhu dulu, memakai pakaian yang rapi dan kopyahan. "Ya persis kayak mau berangkat mengisi pengajian. Padahal saat itu untuk jalan saja ayah harus dibopong," kenang Aminuddin.

Sebagai sang menantu, Dr. Akhmad Sauqi masih ingat dengan betul menit-menit terakhir Kiai Mahsun sebelum meninggal dunia. Diceritakan bahwa sebelum meninggal dunia sekitar jam tiga sore, Kiai Mahsun sempat berwudhu. Dalam benaknya masih memikirkan kemajuan lembaga pendidikan yang didirikannya.

"Beliau pesan kepada calon istri saya saat itu, karena beliau menyimpan uang di saku bajunya sebesar 10 juta. Itu dipesan untuk membelikan seperangkat drum band bagi MI Al-Adnani. Yang uang ada di sakunya lain lagi itu dibuat membayari honor para gurunya," 
ujarnya. Lalu minta dikupaskan jeruk yang kecil-kecil itu, buah kesukaannya. "Setelah sholat dan berdoa, baru beliau menghembuskan nafas terakhirnya," kenangnya.

Sebagai salah tokoh kiai kampung, sosok Kiai Mahsun lekat dalam ingatan warga Desa Kayangan. Modin Suyatno menegaskan bahwa Kiai Mahsun merupakan sosok yang gigih, ulet dan akas dalam berkiprah. "Kemana-mana mengisi pengajian itu ya diantar orang lain dengan dibonceng zaman dulu naik sepeda onthel," kenangnya.

Bagi Abdur Rokhim, sosok Kiai Mahsun adalah inspirator, terutama dalam hal menyampaikan ceramah ataupun sambutan. Termasuk mengabdi ke organisasi NU dan umat secara umum. "Saya sering teringat Kiai Mahsun saat mau sambutan ataupun ceramah, terutama saat ceramah yang diselingi guyonan (joke)," kenangnya.

Dia menilai Kiai Mahsun sebagai sosok yang istikomah dan sederhana. "Ahli ibadah dan selalu berpesan soal itu ke kami bertiga karyawannya," imbuhnya. "Orangnya sabar dalam berinteraksi dengan orang lain, termasuk dengan kami-kami yang menjadi pekerjanya, bahkan seringkali beliau membantu kerjaan kami, biasanya beliau membantu memotong kain-kain 152 yang akan dijahit," ujar bapak tiga putri ini.

Bagi keluarga, terutama anak putra satu-satunya, Aminuddin menegaskan bahwa meninggalnya Kiai Mahsun adalah pukulan dan pengingat buat dirinya secara pribadi. Ini karena kelima anaknya belum ada yang menikah, sedangkan dirinya adalah anak lelaki satu-satunya dan anak tertua. "Akhirnya ketiga adik saya saat menikah saya yang menjadi wali nikahnya," kenangnya dengan mimik serius. Meski sekarang masih ada satu adiknya yang belum menikah.

Hal itu belum ditambah dengan tanggung jawab untuk meneruskan "warisan perjuangan dakwah" Kiai Mahsun, mulai TPQ, masjid, MI dan pengajian-pengajian rutin. "Saya dan adik-adik berkomitmen, meski kita belum mampu mengembangkan, paling tidak kita bisa menjaga keberadaan berbagai warisan perjuangan itu," bebernya.

Kesadaran seperti ini baginya tidak muncul secara tiba-tiba. Karena sebagai anak laki-laki sendiri, nenek dan ayahnya diakui mungkin agak memanjakan. "Jadinya saya akui dulu memang agak nakal, saya mulai sadar saat ayah sakit dan hendak dioperasi punggungnya di rumah sakit," kelasnya. 
Meskipun demikian, Kiai Mahsun memintanya untuk tetap tinggal di rumah menjaga rutinitas masjid dan madrasah. Setelah itu perlahan dirinya mulai sadar soal tanggung jawab sebagai anak laki-laki satu-satunya jika suatu saat ayahnya dipanggil Allah SWT.

Diakui bahwa Kiai Mahsun dalam keluarga adalah sosok yang sabar. "Meskipun saya agak nakal, namun saya tidak pernah dipukul soal kenakalan itu. Kalau mau mengingatkan saya cukup dengan perkataan dan kode saja dengan tangan beliau," ujarnya.

Kelima anak Kiai Mahsun semuanya disekolahkan dan dititipkan ke pondok pesantren, seperti Tebuireng, Paculgowang, Denanyar dan Walisongo. Itu artinya Kiai Mahsun sangat berharap kelima anaknya menjadi orang berilmu yang bersiap meneruskan garis perjuangan yang telah dirintisnya. Di samping itu, sosok Kiai Mahsun diakui banyak orang sebagai kiai yang pintar ngemong masyarakat.

Meskipun variasi orang dalam merespon kegiatan dakwahnya. Meski banyak yang mengikuti dan menerima dakwahnya, masih ada juga yang merintanginya dengan berbagai bentuk. Namun Kiai Mahsun tidak pernah membalas respon negatif dengan hal yang sama. el Bidayah: Journal of Islamic Elementary Education Volume 3, Nomor 2, September 2021
Salah satu contohnya adalah pengajian Muslimat NU yang dirintisnya sejak tahun 1967. Awalnya yang mengikuti hanya enam orang ibu-ibu. Namun berkat kesabaran dalam ngemong masyarakat, tentu dengan tokohtokoh agama yang lain, jamaah pengajian itu menjadi rutin dan banyak pengikutnya. Bahkan tidak hanya diikuti ibu-ibu dari Dusun Kayangan, namun juga dari dusun-dusun sebelah, seperti Dusun Tebon, Dusun Kayen dan Dusun Tungu.

Dusun Tebon yang dulunya masih termasuk "kawasan merah" dan awam soal agama Islam, sekarang sudah banyak anak-anaknya yang bersekolah di MI Al-Adnani. Artinya, sudah ada kesadaran tinggi dalam mempelajari dan mengamalkan ajaran Islam.

Istikomah Kiai Mahsun juga patut ditiru, mulai mengelola lembaga pendidikan (TPQ dan MI), hingga mengurusi masjid. Bahkan saat sudah sakit parah dan tidak bisa jalan, Kiai Mahsun tetap pergi ke masjid dan MI, meski harus naik sepeda motor.

Komitmen tinggi ditunjukkan dari sosok Kiai Mahsun bagi kemajuan dakwah Islam, terutama melalui dunia pendidikan. Tidak sekedar retorika melalui lips service, namun dengan berbagai aksi nyata dan bersentuhan 
Oleh: Mukani

langsung dengan masyarakat. Tidak heran jika kemudian Kiai Mahsun meninggalkan banyak kenangan bagi warga Kayangan.

\section{Sejarah dan Profil MI Al-Adnani}

MI Al-Adnani Kayangan adalah salah satu lembaga pendidikan tingkat dasar di salah satu kecamatan Diwek. Awalnya hanyalah sekelompok anak yang belajar membaca al-Qur'an di musholla al-Qomar. Sebagaian dari analanak iu sekolah di SD dan ada yang tidak sekolah, meskipun sudah usia sekolah. Kondisi ini ditambah lagi dengan masyarakat Kayangan sebagaian besar masih awam tentang pengetahuan agama Islam. Belum lagi adanya sekolah yang bernafaskan Islam di daerah ini.

Keadaan yang seperti ini menggerakkan hati seorang pemuda bernama Muhammad Mahsun untuk berjuang di jalan Allah di bidang pendidikan. Maka didirikanlah sebuah lembaga pendidikan tingkat dasar yaitu MI Al-Adnani Kayangan. Mula-mula proses belajar mengajar betempat di mushalla al-Qomar, karena fasilitasnya kurang memadai kemudian bertempat di gedung SDN Kayangan 1 dan masuk pada siang hari setelah siswa SDN pulang sekolah. ${ }^{17}$

MI Al-Adnani adalah lembaga pendidikan dasar berstatus swasta yang sekarang sudah terakreditasi A. Waktu belajarnya di pagi hari. SK Pendirian madrasah ini adalah Mm.15/3/No. 11/76 tanggal 5 Januari 1976. Berdiri di atas tanah seluas 5460 meter persegi. Lokasinya berada Jalan Masjid AlAdnani Kayangan Gang $1 .^{18}$

Sejarah pendirian MI Al-Adnani di Kayangan dimulai dari keberadaan mushola Al-Qomar yang kemudian berubah menjadi masjid Al-Adnani. Lokasi MI Al-Adnani persis di selatan dari masjid tersebut. Tepatnya di sisi barat jalan desa yang menghubungkan Gang 1 dengan Gang $2 .{ }^{19}$

Saat penulis berkunjung ke lokasi, MI Al-Adnani terlihat tenang dan sepi. Ini dikarenakan pembelajaran dilakukan secara daring (online) pada masa PPKM Darurat pandemi Covid-19. Terlihat beberapa tukang yang melakukan renovasi gedung di sisi barat. Guru dan tenaga pendidikan yang hadir jaga piket juga hanya tiga orang.

\footnotetext{
${ }^{18}$ http://emispendis.kemenag.go.id/dashboard/ index.php?content=madrasah\&action $=\mathrm{lbg} \&$ nss $=11123570025$, diunduh 20 Juli 2021.

${ }^{19}$ Observasi, 15 Juli 2021.
}

${ }^{17}$ Siti Nur Khotimah, "Pengaruh pelaksanaan pendidikan agama dalam keluarga terhadap keaktifan belajar agama siswa kelas V di MI AlAdnani Kayangan Diwek Jombang," Skripsi (Mojokerto: STIT Raden Wijaya, 2012), 52-53. 154 el Bidayah: Journal of Islamic Elementary Education Volume 3, Nomor 2, September 2021 
Diperoleh data bahwa MI Al- batas usia pensiun 60 tahun," beber-

Adnani berada di bawah naungan Yayasan Al-Adnani Kayangan dengan ketua Muhammad Aminuddin, S.Pd.I. Pada tahun pelajaran 2021/2022 ini, susunan pimpinan MI Al-Adnani adalah sebagai berikut:

Kepala Madrasah:

Drs. H. Slamet Suwandi

PKM Kurikulum:

Sulikanah, S.Pd.I.

PKM Kesiswaan:

Sri Rahayu Tri Wahyuni, S.Pd.I.

PKM Sarprashum:

Muh. Afif Zuhri, S.Pd.

Kepala TU:

Lia Rosalia Abidah

Bendahara:

Fitriyah Suciati, S.Ag.

Ketua Komite:

Abdul Munif

Menurut Drs. H. Slamet Suwandi, jumlah siswa baru di MI Al-Adnan tahun ini mengalami peningkatan. "Sekarang mencapai 37 siswa, dari tahun kemarin yang hanya 21 siswa," ujarnya. ${ }^{20}$ Total siswa pada tahun pelajaran ini sebanyak 213 anak.

Kustoyo, S.Pd.I., salah satu guru MI Al-Adnani, menegaskan bahwa di madra-sah ini, ada sebanyak 17 pendidik. "Yang sebanyak 11 guru sudah lulus sertifikasi, namun mulai bulan April 2021 lalu, berkurang menjadi 10 guru, karena Bapak Kamad sudah mencapai

nya. ${ }^{21}$

Berdasarkan cerita yang dia peroleh dan didukung dokumen yang ada, MI Al-Adnani itu berdiri tahun 1976 dan awalnya bertempat di mushola $\mathrm{Al}-$ Qomar yang kemudian berubah nama menjadi Masjid Al-Adnani.

Dikarenakan banyaknya antusiasme siswa yang masuk dan belum memiliki gedung sendiri ketika itu, keberadaan MI Al-Adnani kemudian pindah ke timur jalan raya JombangMalang itu. Saat itu masih pinjam gedung ke SDN Kayangan 1. Jadi masuknya sore hari, karena pada pagi hari gedungnya masih digunakan SDN Kayangan 1 sendiri.

Saat masih meminjam gedung itu, menurut Muhammad Aminuddin, namanya masih MI Darul Hikmah. Namun dikarenakan memiliki kesamaan nama dengan MI di Desa Diwek dan berlokasi masih dalam satu kecamatan, nama itu kemudian diubah menjadi MI Al-Adnani. Penamaan ini disinkronkan dengan nama masjid, yayasan dan TPQ sebagai basisnya. Al-Adnani itu sendiri diambilkan dari nama ayah kandung dari Kiai Mahsun.

${ }^{21}$ Kustoyo, guru MI Al-Adnani, wawancara, 15 Juli 2021. 
Baru pada tahun 1976 MI AlAdnani sudah memiliki gedung sendiri. Lokasinya tidak jauh dari SDN Kayangan 1, tepatnya di selatan masjid Ali Imron, yang kemarin masih difungsikan menjadi RA Muslimat Al-Khodijah. "Baru pada tahun 2002/2003 MI Al-Adnani boyongan ke area sini," kisahnya.

Gedung yang pertama kali dibangun di sini adalah empat ruang kelas di sisi selatan yang menghadap ke utara itu dan tiga kelas sisi barat yang menghadap ke timur. "Jadi bentuknya kala itu seperti huruf L," imbuhnya.

Sebagai sebuah organisasi, tongkat estafet kepemimpinan MI Al-Adnani sudah silih berganti. ${ }^{22}$ Periodesasi kepala MI Al-Adnani Kayangan adalah sebagai berikut:

\begin{tabular}{|c|l|c|}
\hline No & \multicolumn{1}{|c|}{$\begin{array}{c}\text { Nama } \\
\text { Kepala } \\
\text { Madrasah }\end{array}$} & $\begin{array}{c}\text { Periode } \\
\text { Kepemimpinan }\end{array}$ \\
\hline 1 & $\begin{array}{l}\text { KH. } \\
\text { Mahsun } \\
\text { Adnan, BA }\end{array}$ & $1967-2001$ \\
\hline 2 & $\begin{array}{l}\text { Drs. H. Abu } \\
\text { Ma'shum }\end{array}$ & $2001-2008$ \\
\hline 3 & $\begin{array}{l}\text { Lailatul } \\
\text { Qomariyah, } \\
\text { M.Pd.I. }\end{array}$ & $2008-2009$ \\
\hline
\end{tabular}

\begin{tabular}{|c|l|c|}
\hline 4 & $\begin{array}{l}\text { Drs. H. } \\
\text { Nachrowi, } \\
\text { M.Pd.I. }\end{array}$ & \\
\hline 5 & $\begin{array}{l}\text { Drs. H. } \\
\text { Slamet } \\
\text { Suwandi }\end{array}$ & \\
\hline
\end{tabular}

Kurikulum yang digunakan di MI Al-Adnani sini adalah gabungan dari kurikulum nasional di Kemendikbud dan Kemenag. Namun juga ada kurikulum lokal. Muatan lokal yang digunakan seperti nahwu, shorof (Amtsilah Tashrifiyah), Taisirul Kholaq, Akhlaq lil Banin, Mabadi'ul Fiqhiyah, Aqidatul 'Awam dan lain sebagainya. Sedangkan ekstrakurikuler yang ada di MI Al-Adnani meliputi Pramuka, banjari, qiroah, drum band dan kaligrafi.

Sejarah pendirian dan periode awal MI Al-Adnani tidak bisa dilepaskan dari sosok Kiai Mahsun. Dirinya saat itu berstatus sebagai guru PNS dari Depag. Sehingga alur birokrasi pendirian madrasah baru diketahuinya dengan baik. Di samping itu, pengorbanan dan perjuangan Kiai Mahsun pada periode awal MI Al-Adnani tidak diragukan lagi. "Sampeyan bisa tanyakan kepada semua guru yang ada di sana, bagaimana

${ }^{22}$ Dokumen sajarah pendirian MI Al-Adanani Kayangan, tahun 2018. 
perjuangan Kiai Mahsun ke MI AlAdnani," ujar Drs. H. Slamet Suwandi, kepala madrasah sekarang.

Sebagai sosok yang sangat memperhatikan kemajuan dunia pendidikan, dikisahkan oleh Dr. Akhmad Sauqi Ahya, bahwa Kiai Mahsun berjuang keras agar MI Al-Adnani terus bermanfaat bagi masyarakat sekitar. Hal ini bisa dibuktikan dari kurang merawatnya Kiai Mahsun kepada kondisi bangunan rumahnya. "Dari dulu rumahnya ya begitu itu," ujarnya.

Gaji Kiai Mahsun selaku PNS guru di Depag, lanjutnya, tidak pernah diambil. Yang mengambil itu malah teman mengajarnya di MI Al-Adnani. "Saya lupa namanya, tetapi rumahnya di Desa Keras Kidul sana, sekarang menantu beliau juga mengajar di MI AlAdnani," terangnya. Gaji Kiai Mahsun diambilkan setiap bulan dari KUA Diwek lalu dibuat membayari gaji para guru di MI Al-Adnani.

Sisi lain kiprah dan perjuangan Kiai Mahsun dalam mendirikan MI AlAdnani diungkapkan Muhammad Aminuddin, putra sulungnya. Pada masa awal pendirian MI dan masjid Al-Adnani, kisahnya, Kiai Mahsun lebih banyak didampingi oleh Sugiharto. "Beliau adik kandungnya modin Suyatno, punya rumah di belakang rumahnya Modin," ujarnya.

Sugiharto ini menjadi ketua remaja masjid saat zaman Kiai Mahsun masih hidup. Orang ini juga mengajar di MI AlAdnani periode awal saat masih berlokasi di timur jalan. Sekarang orang ini tinggal di Surabaya, juga mengurusi masjid.

Pada periode awal MI Al-Adnani, Kiai Mahsun juga memiliki banyak relasi teman dalam mengembangkan lembaga pendidikannya. "Teman akrabnya yang juga berstatus saat itu ya Ibu Sriyati, guru MI Al-Adnani juga yang rumahnya Desa Keras. Teman lainnya adalah Pak Bilal, rumahnya di Dusun Kayen sana," kenangnya.

Dirinya mengaku memang pernah mendengar cerita jika gaji Kiai Mahsun sering diambilkan temannya itu untuk kemudian digunakan untuk operasional MI Al-Adnani. "Terutama untuk membayar gaji para guru dan karyawannya," imbuhnya.

MI Al-Adnani, lanjutnya, pernah hendak diubah statusnya menjadi negeri. Ini dimaklumi karena di wilayah kecamatan Diwek, belum ada MI berstatus negeri. Namun dengan berbagai pertimbangan, terutama dalam menjaga keberadaan ilmu-ilmu keagamaan, 
rencana proses penegerian itu ditolak secara halus.

\section{Pembahasan}

Perjuangan seorang tokoh dalam mengembangkan ajaran Islam di suatu wilayah, biasanya memiliki cakupan yang cukup luas. Hal ini juga bisa dilihat dari sosok Kiai Mahsun yang berkiprah di Desa Kayangan. Tidak hanya di bidang dakwah, tetapi juga berusaha meningkatkan kualitas hidup warga sekitar dalam memahami ajaran Islam, melalui jamaah pengajian di bawah naungan organisasi NU.

Di samping itu, kiprah itu juga dibuktikan dengan aktif berkegiatan di dunia dakwah. Tidak sekedar di satu Desa Kayangan saja, namun juga ke desa-desa dan kecamatan-kecamatan sekitar. Bahkan juga beberapa melalui berdakwah hingga ke luar daerah kabupaten.

Hal ini menunjukkan kiprah yang tidak sedikit. Termasuk di dalam memajukan dunia pendidikan dengan mendirikan lembaga pendidikan bernama MI Al-Adnani. Madrasah ini adalah jawaban konkrit dari Kiai Mahsun dalam merespon masih rendahnya kualitas beragama dan minimnya pemahaman warga sekitar terhadap ajaran Islam, terutama bagi anak-anak selaku calon generasi penerus bangsa.

MI Al-Adnani mulai berdiri hingga sekarang tetap menunjukkan komitmennya dalam melayani masyarakat di dunia pendidikan. Konsistensi untuk memberikan yang terbaik ini dibuktikan dengan nilai akreditasi A. Di samping itu, biaya yang terjangkau juga diberikan kepada para siswa. Ini mengingat madrasah adalah lembaga non-profit.

Kesederhanaan dan keikhlasan para dewan guru dalam mendidik anak bangsa juga ditunjukkan. Ini semua mengindikasikan secara kuat bahwa menjadi pendidik adalah panggilan jiwa untuk berjuang dengan model lain, tidak melulu di medan perang. Banyak dewan guru di MI Al-Adnani Kayangan adalah alumni dari madrasah ini. Hal itu berarti mereka tahu persis bagaimana sosok Kiai Mahsun menjadi guru ketika masih hidup. Nilai-nilai yang sudah dibiasakan Kiai Mahsun saat menjadi pendidik itulah yang diakui para guru untuk hendak diteruskan dan dipertahankan. Tentu dengan berbagai upaya-upaya untuk terus memajukan MI Al-Adnani Kayangan ini.

Sebagai salah satu tokoh kiai kampung, sosok Kiai Mahsun lekat dalam ingatan warga Desa Kayangan. 
Bagi banyak warga, sosok Kiai Mahsun adalah inspirator, terutama dalam hal mengabdi ke organisasi NU dan umat secara umum. Ini karena Kiai Mahsun dinilai sebagai sosok yang istikomah dan sederhana.

Sosok Kiai Mahsun diakui banyak orang sebagai kiai yang pintar ngemong masyarakat. Meskipun variasi orang dalam merespon kegiatan dakwahnya. Meski banyak yang mengikuti dan menerima dakwahnya, masih ada juga yang merintanginya dengan berbagai bentuk. Namun Kiai Mahsun tidak pernah membalas respon negatif dengan hal yang sama.

\section{Kesimpulan}

Berdasarkan paparan hasil penelitian dan pembahasan di atas, maka yang menjadi kesimpulan dari penelitian ini adalah dua hal. Pertama adalah biografi Kiai Mahsun dimulai kelahiran di Dusun Nglaban, lalu menimba ilmu ke Tebuireng, PGA dan kuliah di Undar lalu mengabdikan diri bagi dakwah dan dunia pendidikan hingga wafatnya.

Kedua adalah pendirian dan perkembangan MI Al-Adnani Kayangan tidak lepas dari tangan dingin Kiai Mahsun, mulai dari menjadi merintis, menjadi kepala madrasah, mengajar di dalamnya hingga berjuang agar madrasah tersebut tetap berkiprah. Hingga sekarang, MI Al-Adnani Kayangan tetap menunjukkan eksistensinya dalam memajukan warga masyarakat sekitar melalui dunia pendidikan, dengan disertai proses berkualitas.

\section{Daftar Pustaka}

Arikunto, Suharsimi. Prosedur Penelitian. Jakarta: Rineka Cipta, 2010.

Aminuddin, Muhammad. Ketua Yayasan Al-Adnani, wawancara, 27 Februari 2021.

Ahya, Akhmad Sauqi. Menantu Kiai Mahsun, wawancara, 9 Februari 2021.

Dokumen sajarah pendirian MI AlAdanani Kayangan, tahun 2018.

Drajat, Manpan. "Sejarah Madrasah di Indonesia," al-Afkar: Journal for Islamic Studies, Vol. 1 No. 1 (Januari 2018).

Haderani. "Pesantren, Madrasah dan Sekolah Dalam Perspektif Pemikiran Pendidikan Islam," Jurnal Tarbiyah Darussalam, Vol. 4 No. 6 (2020).

Hadi, Sutrisno. Metodologi Research. Yogyakarta: Andi Offset, 1987.

Haningsih, Sri. "Peran Strategis Pesantren, Madrasah dan Sekolah Islam di Indonesia," El-Tarbawi, Vol. 1 No. 1 (2008). 
Hasri. "Madrasah Sebagai Lembaga Pendidikan Islam," AlKhwarizmi, Vol. 2, No. 1 (Maret 2014).

http://emispendis.kemenag.go.id/dash board/index.php?content $=\mathrm{m}$ adrasah\&action $=$ lbg\&nss $=11$ 123570025, diunduh 20 Juli 2021.

Khotimah, Siti Nur. "Pengaruh pelaksanaan pendidikan agama dalam keluarga terhadap keaktifan belajar agama siswa kelas V di MI AlAdnani Kayangan Diwek Jombang," Skripsi. Mojokerto: STIT Raden Wijaya, 2012.

Kustoyo. Guru MI Al-Adnani, wawancara, 15 Juli 2021.

Mizani, Hilmi. "Pendidikan Madrasah: Kebijakan dan Sistem Madrasah di Indonesia," Jurnal Tarbiyah Islamiyah, Vol. 3 No. 2 (2013).

Moleong, Lexy J. Metodologi Penelitian Kualitatif. Bandung: Remaja Rosdakarya, 2010.

Muhajir, Noeng. Metodologi Penelitian Kualitatif. Yogyakarta: Reke Sarasean, 2014.

Nasution, S. Metode Penelitian Naturalistik Kualitatif. Bandung: Tarsito, 2012.

Nazir, Moh. Metode Penelitian. Jakarta: Balai Aksara, 2015.
Qomariyah, Lailatul. "Pemanfaatan Aplikasi Kahoot Pada Evaluasi Jombang," Prosiding Seminar Nasional Sainsteknopak 2020, Universitas Hasyim Asy'ari Tebuireng Jombang.

Rokhim, Abdur. Kepala TK Al-Husaini Kepuhpandak, wawancara, 11 Juli 2021.

Suwandi, Slamet. Kepala MI Al-Adnani, wawancara, 10 Juli 2021.

Observasi, 15 Juli 2021. 